\title{
§ I The Nineveh Manuscripts of Chapter One (IGI 1)
}

TITLE

\author{
IF A MAN'S EYES ARE SICK \\ šumma(DIŠ) amēlu(NA) īnāšu(IGI.MIN-šú) marșā(GIG) \\ = Assur Medical Catalogue 1. 8 .
}

\begin{abstract}
Sigla notations:
$\mathbf{N}=$ Nineveh, Neo-Assyrian. A, B, C, ... designate the different manuscripts.

Translation in italics are tentative reconstructions based on parallels.
\end{abstract}

Base Manuscript: NA (BAM 510), collated.

Museum number: $\quad$ British Museum, K 2573 + 3465 + 6950 + 7241 + 8368+8997+ 10321

$+10613+10891+12000 p+12831+13393+13482+$ BU 89-4-26, 155

$+\mathrm{Rm} 264+$ Sm 1464 (+) K 11847 [col. iii 17ff.] (+) K 13465 [AMT 18/1

= bot. col. iii].

Origin and date: Nineveh, $7^{\text {th }}$ century BC.

Type of tablet: Two-column, portrait-oriented tablet. The two dividing rulings were made by a twisted thread and several round holes are visible at empty spaces.

Measurements: $\quad$ ca. $25 \times 16,8 \times 2,9$ (upper edge) $-3,6$ (towards the middle) $\mathrm{cm}$.

Copy: $\quad$ BAM 510, AMT 18/1.

Photo/CDLI nr.: $\quad$ Plates 1-7/P394523.

Literature: $\quad$ Köcher 1980b: ix-xi, BAM 510; Geller 1984: 293ff.; Collins 1999: 94 note 39, 203ff., 206ff., 208ff., 210ff. 214ff., 216ff., 218ff., 220ff., 222ff., 225ff.; Fincke 2000: 330. Scurlock and Andersen 2005: 793; Foster 2005: 969f.; Fincke 2009; Geller 2007c: 392; Geller 2009: 5. Geller 2010a: 92ff., 107; Geller 2010b: 61ff.; Lambert 2013: 399f.; Scurlock 2014: 756; Attia 2015.

Duplicate 1: $\quad$ NB (BAM 513), collated.

Museum number: British Museum, K 2570 + 3425+5000+7105+11683 + 13389+ BM $98942+$ DT $172+$ DT $371+$ Rm 2, $381+$ Sm $821+79-7-8,192+82-3-$ 23, 41 (+) 79-7-8, 156 [AMT 8/3].

Origin and date: Nineveh, $7^{\text {th }}$ century BC.

Type of tablet: $\quad$ Two-column, portrait-oriented tablet. The two vertical dividing rulings were done with an instrument, presumably with the stylus. There are numerous round holes visible at empty spaces and the sides of the tablet.

Measurements: $\quad$ ca. $25 \times 16,6 \times 2,4$ (lower edge) $-2,8$ (towards the middle) $\mathrm{cm}$.

Copy: BAM 513; Farber 1998: 68; AMT 8/3.

Photo/CDLI nr.: $\quad$ Plates 7-12/P394520. 
Literature:

Duplicate 2:

Museum number:

Origin and date:

Type of tablet:

Measurements:

Copy:

Photo/CDLI nr.:

Literature:
Köcher 1980b: xi, BAM 513; Geller 1984: 293ff.; Farber 1998: 65ff.; Collins 1999: 203ff., 206ff., 208ff., 210ff. 213ff., 218ff., 220ff., 222ff.; Fincke 2000: 330. Scurlock and Andersen 2005: 793; Foster 2005: 969; Geller 2007c: 392; Fincke 2009; Geller 2009: 5. Geller 2010a: 107; Geller 2010b: 61ff.; Scurlock 2014: 756; Attia 2015.

NC (BAM 514), collated. (The line numeration does not always follow BAM 514).

British Museum, K 2456 [AMT 20/2] + K 2970 + K 2980 + Sm 1897 (+) K 8824 (+) K 2979 (+) K 14879 (courtesy E. Jiménez). K 8824 is a direct join, but cannot be physically attached due to the rough gypsum, which holds the other pieces together.

Nineveh, $7^{\text {th }}$ century BC.

Two-column, portrait-oriented tablet. The two vertical dividing rulings of the tablet were done with an instrument, presumably with a stylus. Occasionally, round holes are visible at empty spaces and on the sides of the tablets.

ca. $25 \times 16,3 \times$ ca. 2,8 (lower edge) - 3,1 (towards the middle) $\mathrm{cm}$. BAM 514; AMT 20/2; Plate 18. Plates 12-18/P394759 (K 14879, P401052).

Köcher 1980b: xi, BAM 514; Geller 1984: 293ff.; Farber 1998: 65; Collins 1999: 203ff., 206ff., 208ff., 210ff. 213, 214f., 216ff., 218, 219, 220ff., 222ff., 225ff.; Fincke 2000: 330f.; Scurlock and Andersen 2005: 793; Foster 2005: 968f.; Geller 2007c: 392; Fincke 2009; Geller 2009: 5. Geller 2010a: 107; Geller 2010b: 61ff.; Attia 2015.

\section{§ I.1 Related Manuscripts containing IGI 2 and 3 from Nineveh}

The texts included represent parallels and partial parallels from the other tablets of the IGI treatise.

Manuscript: $\quad$ ND (BAM 515), see § II.1, parallels: 23ff.', 184’, 200’.

Manuscript: $\quad$ NE (BAM 516), see § III.1, parallels: 32f.', 184’.

\section{§ I.2 Related other Manuscripts from Nineveh}

The texts included represent parallels and partial parallels which are considered important for the compilation of the IGI-treatise. They come from other tablets and fragments from Nineveh containing prescriptions for sick eyes or from the UGU-treatise. 
Manuscript: $\quad$ NJ (AMT 12/5), collated, parallels: 61ff.'.

Museum number: British Museum, K 5852.

Origin and date: Nineveh, $7^{\text {th }}$ century BC.

Type of tablet: The two-column portrait-oriented tablet is too fragmentary to judge but might be a fourth duplicate to IGI Tablet One.

Measurements: ca. $2,3 \times 3 \times 1,4 \mathrm{~cm}$

Copy: $\quad$ AMT $12 / 5$.

Photo/CDLI nr.: $\quad$ Plate 42/P396208.

Manuscript: $\quad$ NQ (BAM 521), see § IV. 4, parallels: 35’

Manuscript: $\quad$ NU (AMT 14/3), see § IV.8, parallels: 81’.

\section{$\S 1.3$ Related Manuscripts from Different Cities}

The texts included here represent parallels and partial parallels which are considered important for the compilation of the IGI-treatise. These are manuscripts coming from other periods and from cities other than Nineveh.

\section{Sigla notations:}

A = Assur, Late Assyrian. A, B, C, ... designate the different manuscripts.

Am $=$ Assur, Middle Assyrian. A, B, C, ... designate the different manuscripts.

$\mathbf{b}=$ Babylon, Late Babylonian. $\mathrm{A}, \mathrm{B}, \mathrm{C}, \ldots$ designate the different manuscripts.

$\mathrm{E}=$ Emar, Middle Babylonian. $\mathrm{A}, \mathrm{B}, \mathrm{C}, \ldots$ designate the different manuscripts.

$\mathbf{H}=$ Huzirina, Late Assyrian. A, B, C, ... designate the different manuscripts.

$\mathbf{s}=$ Sippar, Late Babylonian. $A, B, C, \ldots$ designate the different manuscripts.

$\mathbf{U}=$ Ugarit, Middle Babylonian. $\mathrm{A}, \mathrm{B}, \mathrm{C}, \ldots$ designate the different manuscripts.

$\mathbf{u}=$ Uruk, Late Babylonian. $A, B, C, \ldots$ designate the different manuscripts.

$\mathbf{x}=$ unknown provenance, Late Babylonian. $\mathrm{A}, \mathrm{B}, \mathrm{C}, \ldots$ designate the different manuscripts.

Initial capital letters designate tablets in Assyrian script or northern scripts, and small letters tablets in Babylonian script.

Parenthesis [0] on a siglum designate a parallel text and not a duplicate.

\section{Assyrian}

Manuscript: $\quad$ AmA (BAM 165), collated, parallels: 32f.'.

Museum number: $\quad$ Vorderasiatisches Museum, Berlin, VAT $9467+10300+10414+$ $12261(+) 11824$.

Origin and date: Assur, Middle Assyrian.

Type of tablet: $\quad$ Fragments of a multi-column tablet.

Measurements: $\quad$ VAT $9467+$ ca. $11,3 \times 7,3 \times 3,2 \mathrm{~cm}$. // VAT $11824 \mathrm{ca} .3,1 \times 3,9 \times 2 \mathrm{~cm}$. 
CDLI nr.:

Literatur:

Manuscript:

Museum number:

Origin and date:

Type of tablet:

Measurements:

Copy:

CDLI nr.:

Literature:

Manuscript:

Museum number:

Origin and date:

Type of tablet:

Copy:

Photo/CDLI nr.:

Literature:
Copy:

BAM 165; KAL 4/52; Copy of VAT 11824 in notes to IGI 132 '. P281813.

Köcher 1963b: xvii; secondary literature in Maul and Strauß 2011: no. 52; Geller 2011: 340ff.

AA (BAM 20), collated, parallels: 23ff.', 32ff.'.

Vorderasiatisches Museum, Berlin, VAT 8281.

Assur, Neo-Assyrian.

Poorly preserved narrow, one-column, portrait-oriented tablet. ca. 8,1 ×4,2×1,1-1,9 (towards the middle) $\mathrm{cm}$.

BAM 20, KAR 183.

P285122.

Köcher 1963a: xv; Fincke 2000: 329; Böck 2004: 38; Scurlock and Andersen 2005: 784. Scurlock 2014: 753; Attia 2015: 9, 10, 38, 45, 72.

AB (BAM 159), collated, parallels: 23ff.', 41’.

Istanbul, A 198.

Assur, Late Assyrian.

Three-column tablet.

BAM 159;

Plates 42-43/P285254.

Köcher 1963b: xivff.; edition and literature in Parys 2014; Scurlock 2014: 754; Attia 2015: 9, 11, 31, 45.

Manuscript:

AC (BAM 19), collated with a photo by M. Guichard, parallels: 32ff.'.

Museum number:

École Pratique des Hautes Études, Paris, EHE 330.

Origin and date: Assur, Late Assyrian? However, the copy shows some signs (like BA in úMAŠ.TAB.BA) in more Middle Assyrian palaeography.

Type of tablet: $\quad$ Fragment of presumably one-column tablet.

Copy: $\quad$ BAM 19.

Photo/CDLI nr.: $\quad$ Plates 49/P285121.

Literature:

Scheil, V. 1921: 6ff. Köcher 1963a: xv; Fincke 2000: 329; Scurlock and Andersen 2005: 784; Attia 2015: 9f.

Manuscript: $\quad$ AD (BAM 22), collated, parallels: 61ff.'.

Museum number: $\quad$ Vorderasiatisches Museum, Berlin, VAT 13732.

Origin and date: Assur, Late Assyrian.

Type of tablet: $\quad$ Lower half of a one-column, portrait-oriented tablet.

Measurements: $\quad 7 \times 6,4 \times 1,8-2,7$ (towards the middle) $\mathrm{cm}$.

Copy: $\quad$ BAM 22.

CDLI nr.: $\quad$ P285124. 
Literature:

Köcher 1963: xv; Hannen 2014; Scurlock 2014: 753. Attia 2015: 13, 32, 39, 40, 44.

Manuscript:

AE (BAM 18), collated, parallels: 41'.

Museum number:

Origin and date:

Vorderasiatisches Museum, Berlin, VAT $9896+10895+12399$.

Type of tablet:

Assur, Late Assyrian.

Measurements:

One-column, landscape-oriented tablet.

Copy:

ca. $6,9 \times 12,5 \times 1,4-2,3$ (towards the middle) $\mathrm{cm}$.

CDLI nr.:

BAM 18.

Literature:

P285120.

Köcher 1963: xv; Fincke 2000: 329; Scurlock and Andersen 2005: 779; Scurlock 2014: 753. Attia 2015: 11, 31.

Manuscript:

AX (KAL 7/12), collated, parallels: 100ff.'.

Museum number:

Vorderasiatisches Museum, Berlin, VAT 11096.

Origin and date: Assur, Late Assyrian.

Type of tablet:

Fragment from the middle part of a two- or more column tablet. Some signs suggest also earlier dating (Meinhold 2017: 53 fn. 15'). There are tiny round holes made presumably by a straw.

Measurements: $7,8 \times 7,4 \times 1,0 \mathrm{~cm}$.

Copy: KAL 7/12

Literature:

Meinhold 2017: no. 12.

Manuscript:

HA (STT 279), photo collated, parallels: 159ff.'.

Museum number:

Anadolu Medeniyetleri Müzesi, Ankara, 51/72+83.

Origin and date:

Huzirina, Late Assyrian.

Type of tablet:

One-column, elongated portrait oriented tablet.

Measurements: $\quad 11,5 \times 4,5 \mathrm{~cm}$.

Copy:

STT 279.

CDLI nr.:

P338597.

Literature:

Fincke 2000: 335f.; Foster 2005: 969. Scurlock and Andersen 2005: 806; Attia 2015: 19f., 55.

\section{Babylonian}

Manuscript:

bA (BM $41293+$ ), collated, parallels: 41'.

Museum number:

British Museum, London, BM $41293+44866$

Origin and date:

Babylon, Late Babylonian.

Type of tablet:

Upper part of two-column, portrait or landscape-oriented tablet.

Measurements:

$13,4 \times 9,8 \times 2,6 \mathrm{~cm}$

Copy:

Geller 2010a: 16, fig. 1.1; Plate 43. 
Photo: $\quad$ Plate 42.

Literature: Geller 2010a: 16.

Manuscript: $\quad$ sA (Iraq 65), collated with a photo, parallels: 32f.'.

Museum number: National Museum of Iraq, Baghdad, IM 132670.

Origin and date: Sippar, Late Babylonian.

Type of tablet: Two-column, portrait oriented tablet.

Measurements: $21,5 \times 13,3 \mathrm{~cm}$.

Copy: $\quad$ Iraq 65: 223, 229.

Photo/CDLI nr.: $\quad$ Heeßel and al Rawi 2003: 222, 224, 228, 230/P404959.

Literature: $\quad$ Heeßel and al Rawi 2003; Scurlock 2014: 760; Attia 2015: 23, 37, 41, 64.

Manuscript: $\quad$ uA (SpTU 50), not collated, parallels: 184’.

Museum number: National Museum of Iraq, Baghdad, Excavation no. W 22664.

Origin and date: Uruk, Late Babylonian.

Type of tablet: One-column, portrait oriented tablet.

Measurements: $\quad 6,5 \times 5,1 \mathrm{~cm}$.

Copy: $\quad$ SpTU 50 .

CDLI nr.: $\quad$ P348655.

Literature: $\quad$ von Weiher 1983: no. 50; Fincke 2000: 335; Scurlock and Andersen 2005: 803f.; http://oracc.org/cams/gkab/P348655; Scurlock 2014: 762. Attia 2015: 8, 71, 79.

Manuscript: $\quad$ xA (CM 37), collated, parallels: 36ff.', 61ff.', 184’.

Museum number: British Museum, BM $54641+54826$

Origin and date: Provenance Sippar (according to the British Museum Collection online), or Borsippa (according to Fincke 2009: 84). Late Babylonian.

Type of tablet: One-column, portrait oriented tablet.

Measurements: $\quad 7,3 \times 8,2 \times 2,9 \mathrm{~cm}$.

Copy:

Fincke 2009: 87, 89.

Photo:

Fincke 2009: 102f.

Literature:

Leichty 1986: 152, 157; Fincke 2009; Scurlock 2014: 759; Attia 2015: 6, 10, 13, 29, 37, 39, 71, 79 . 


\section{Periphery}

\section{Emar}

Manuscript:

EA (EMAR 6/4), not collated, parallels: 91', 94f.', 103', 136'.

Museum number:

National Museum of Syria, Aleppo? Msk 731030

Origin and date:

Emar, Middle Babylonian.

Type of tablet:

CDLI nr.:

One-column, portrait oriented tablet.

Literature: P271301.

Arnaud 1987: 345f.; Viano 2016: 417; SEAL 5.3.8.1.

\section{Ugarit}

Manuscript:

UA (AuOrS 23/27), photo collated, parallels: 73', 89'.

Museum number:

National Museum of Syria, Damascus, RS 25.418.

Origin and date: Ugarit, Middle Babylonian.

Type of tablet: Too fragmentary for certainty.

Copy: Arnaud 2007: plate xiii no. 27.

Photo/CDLI nr.: del Olmo Lete 2014: plate XVIII.

Literature: Arnaud 2007: 98f.; del Olmo Lete 2014: 69ff.; Viano 2016: 406.

Manuscript: $\quad$ UB (Ugaritica 5), photo collated, parallels: 91', 136'.

Museum number: $\quad$ National Museum of Syria, Damascus, RS 20.006.

Origin and date: Ugarit, Middle Babylonian.

Type of tablet: One-column, landscape-oriented tablet.

Copy: Nougayrol 1968: no. 19

Literature:

Nougayrol 1968: 64f.; Fincke 2000: 338; Foster 2005: 967; Westenholz 2010: 389; del Olmo Lete 2014: 69ff.; SEAL 5.3.8.2.

Manuscript: $\quad$ UC (AuOrS 23/14), not collated, parallels: 93', 98', 110'.

Museum number: $\quad$ National Museum of Syria, Damascus, RS 94.2178.

Origin and date: Ugarit, Middle Babylonian.

Type of tablet: One-column, landscape-oriented tablet.

Literature: $\quad$ Arnaud 2007: plate xif. no. 14; del Olmo Lete 2014: 59ff.; Viano 2016: 406.

\section{§ I.4 Synopsis of the Prescriptions of Chapter One (IGI 1)}

1ff.' Fragmentary prescriptions: preparation of medication in a bowl, daubing the eyes.

6f.' No diagnosis (but presumably as the previous one): medication with minerals, bat guano, bones, bone marrow, all pounded and blown into the eyes. 
8f.' Medical application prescription for tying braided wool on the head containing sesame oil and plants, repeated over three days, daubing?

10f.' Prescription for sick eyes: plants, minerals and ghee, pounded in the sap of a kasû-plant, bandaging; minerals drenched in fat and pounded and mixed in ghee, daubing.

12f.' Prescription for sick eyes: sesame oil smeared on the temples; bandage with copper patina on the head temples; exudation of copper and minerals mixed in ghee, daubing the eyes: prognosis for recovery.

14f.' Prescription for sick and burning eyes: copper patina mixed in ghee, daubing; cutting garlic with a bronze knife, three times daubing; plant kneaded in beer dregs, bandaging.

16f.' Prescription for sick and burning eyes: parched and crushed copper patina, pounded in ghee, daubing.

18ff.' No diagnosis (but presumably same as the previous one): plant boiled in beer dripped into the eyes; preparation of plant mixture, bandaging; salve from condensed reddish kidney fat pounded on a spoon, daubing.

21f. Prescription for sick and closed eyes: rinsing seeds and plants, bandaging; medication of plants, daubing.

23ff. Prescription, known from numerous sources, for sick eyes, which cannot be opened for many days, being accompanied with fever: shaving the head, cooling it with dough; salve of plants and ghee on spoon, daubing.

26' Prescription for dry eyes: onion being chopped by the patient, drunk in beer, sprinkling oil into eyes: prognosis for recovery.

27 No diagnosis (but presumably same as the previous one): swallowing a pill on an empty stomach, consisting of powder of date stones kneaded in the sap of a kasû-plant.

28 No diagnosis (but presumably same as the previous one): salve of frog's bile mixed in ghee, daubing.

29' No diagnosis (but presumably same as the previous one), mixture of plant powder and flour kneaded in the sap of a kasû-plant, bandaging eyes and temples.

30f.' Fragmentary incantation for activating substances.

32f.' Prescription for sick eyes, known from numerous sources: plants roasted over charcoal, stirred in ghee, a sheep's kidney fat, wax, daubing.

34' Prescription for sick eyes: daubing the eyes with simplicia: plant and bat guano mixed in ghee, daubing.

35' Prescription for sick eyes: daubing the eyes with simplicia: a mineral pounded in ghee, a plant boiled in milk, bandaging.

36ff.' Prescription for eyes full of blood, including sleepless state with closed eyes: mixture of parched plant, a sheep's dung in the milk from a woman in maternity, bandaging. In the morning loosening the bandage, daubing the eyes 
with salve from pounded mineral in ghee, plant medication, bandaging the eyes with the plant wrapped in red and white wool, daubing.

40ff.' Prescription for eyes suffused with blood: mixture of plants and paste in honey, daubing; mixture of bat guano, plant and saline solution, daubing.

42' No diagnosis (but presumably same as the previous one): dryed plant spattered into the eyes, paste in ghee, presumably daubing.

43' No diagnosis (but presumably same as the previous one): lizard excrement in bone marrow, no consumption, presumably daubing or oral intake.

44' No diagnosis (but presumably same as the previous one): simplicia in oil and ghee, daubing.

45 Prescription for eyes full of blood: salve of simplicium in ghee, daubing.

46' No diagnosis (but presumably same as the previous one): salve of plants in ghee, daubing.

47' No diagnosis (but presumably same as the previous one): daubing with simplicia: pounded mineral in spittle, pounded mineral in the milk from a woman in maternity, daubing

48 No diagnosis (but presumably same as the previous one): dripping pig blood into the eyes.

49ff.' Fragmentary prescriptions for different seasons, plants mixed in different solvents depending on the season, daubing; blowing medication into the eyes.

57 Prescription for [sick eyes]: plants and powder mixture, drunk in wine.

58' No diagnosis (but presumably same as the previous one), salve of plants and stones pounded in ghee, daubing.

59f.' Prescription for sick eyes: bandaging; a mineral pounded in ghee, daubing.

61ff.' Prescription for bloody eyes: mixture of bat guano, saline, plants ground together in a sheep's bile, seasonal application, the mixture dissolved in different solvents depending on the season, daubing.

64' No diagnosis (but presumably same as the previous one): mixture of bat guano in mountain honey, daubing. This is a drug which is to be used for twenty days.

65ff.' Incantation for blood in the eyes.

69' Medical application with plants, knotted together, accompanying the previous incantation and recited over the fourteen plant knots.

70f.' Incantation for blood in the eyes.

72' Medical application accompanying the previous incantation: a mineral pounded in ghee, applied into the eyes.

73ff.' Incantation for blood in the eyes.

78' Medical application accompanying the previous incantation: pounded plant, resin, lizard excrement stirred in goat's milk, bandaging. 
79ff.' Prescription for sick eyes with blood, tears, and film, accompanied by blurred vision: plant sap, dissolved in vinegar, macerated overnight under stars, processed in the morning, mixed with minerals, copper exudation and plants. All stirred together in rinsed vessel, kneaded in ghee and (pounded) mineral. The upper part of the eyes opened with the healer's finger and the medication applied onto the eyes. Then eyes must be kept closed and rubbed with the mixture for nine days.

86' Prescription for the same case: plant simplicium mixed in saline solution, and blown via a bronze tube into the eyes.

87 Alternative prescription for the same case: pounded exudation of copper and white plant blown into the eyes via a bronze tube.

88' Alternative prescription for the same case: pounded plants blown into the eyes via a bronze tube.

89ff.' Incantation for sick eyes.

97' Medical application accompanying the previous incantation recited over seven knots of white wool.

98ff.' Incantation for sick eyes.

109' Medical application accompanying the previous incantation recited over seven knots of red wool.

110ff.' Incantation for sick eyes.

117f.' Medical application accompanying the previous incantation recited over seven knots of red and white wool. Tying cords of red wool on the sick eye, and cord of white wool on the healthy eye: prognosis for recovery.

119ff.' Incantation for sick eyes with the same medical application as the previous one.

125ff.' Incantation for sick eyes with the same medical application as the previous one.

132ff.' Incantation for sick eyes with the same medical application as the previous one.

136ff.' Fragmentary incantations and medical applications.

150ff.' Incantation for sick eyes.

154' Medical application accompanying the previous incantation recited over seven knots of red and white wool: prognosis for recovery.

155f.' Incantation for sick eyes with the same medical application as the previous one.

157f.' Incantation for sick eyes with the same medical application as the previous one.

159ff.' Incantation for sick eyes with the same medical application as the previous one: prognosis for recovery.

163ff.' Bilingual incantation for sick eyes, without accompanying medical application.

176ff.' Incantation for sick eyes. 
180f.' Medical application accompanying the previous incantation recited over tampons of red and white wool, red wool tampon applied on the sick eye, and the white one on the healthy: prognosis for recovery.

182ff.' Incantation for murky eyes.

185f.' Medical application with a sheep's knee, accompanying the previous incantation recited over seven knots: prognosis for recovery.

187ff.' Incantation for removing foreign objects from the eye as chaff, sherd or anything, without accompanying medical application.

194ff.' Incantation for removing the foreign object/disease (merhu) from the inside of the eyes.

200ff.' Catchline of chapter (tablet) two, name of chapter one, and not preserved Ashurbanipal colophon. 